\title{
Undiagnosed Traumatic Tricuspid Regurgitation Identified by Intraoperative Transesophageal Echocardiography
}

\author{
Yun Yong Jeong, M.D.*, Jonghwan Moon, M.D. ${ }^{\dagger}$, Sang Hyun Lim, M.D., Ph.D. ${ }^{\ddagger}$, \\ Yeo Jin Kim, M.D.*, Hyoeun Ahn, M.D.*, Sung Yong Park, M.D.* \\ ${ }^{*}$ Department of Anesthesiology and Pain Medicine, ${ }^{\dagger}$ Division of Trauma Surgery, Department of Surgery, and \\ ${ }^{\ddagger}$ Department of Thoracic and Cardiovascular Surgery, Ajou University School of Medicine, Suwon, Korea
}

Correspondence to:

Sung Yong Park, M.D.

Department of Anesthesiology and Pain Medicine, Ajou Uni-

versity School of Medicine, 164

WorldCup-ro, Yeongtong-gu,

Suwon 16499, Korea

Tel: +82-31-219-5573

Fax: +82-31-219-5579

E-mail: anepark@hanmail.net
In the critically injuried and hemodynamically unstable patient, extended focused assessment with sonography for trauma (E-FAST) examination can be performed for a rapid assessment of peritoneal and/or pericardial fluid. We report a case of traumatic tricuspid regurgitation that was missed in the emergency department by E-FAST and identified by intraoperative transesophageal echocardiography. (J Acute Care Surg 2016;6:68-70)

Key Words: Echocardiography, Tricuspid valve, Thoracic injuries

Received February 15, 2016, Revised April 20, 2016, Accepted May 17, 2016

Copyright $\odot 2016$ by Korean Society of Acute Care Surgery

(c) This is an Open Access article distributed under the terms of the Creative Commons Attribution Non-Commercial License (http://creativecommons.org/licenses/by-nc/4.0) which permits unrestricted non-commercial use, distribution, and reproduction in any medium, provided the original work is properly cited.

\section{Introduction}

High-speed automobile accidents are a leading cause of isolated traumatic tricuspid regurgitation, a complication of blunt chest trauma [1]. Although early diagnosis is important because traumatic tricuspid injury could be effectively corrected with reparative techniques. Early operation is considered to relieve symptoms and to prevent right ventricular dysfunction, diagnosis may be delayed or missed because traffic accidents have coexisting urgent issues [2]. We report a case of traumatic tricuspid regurgitation that was missed in the emergency department and identified by intraoperative transesophageal echocardiography (TEE) in a patient who presented to the emergency department after blunt chest trauma from a motor vehicle accident.

\section{Case Report}

A 57-year-old man with a history of hypertension presented to the emergency department after a motor vehicle accident. Vital signs in the emergency room were blood pressure $73 / 58 \mathrm{mmHg}$, heart rate 140 beats per minute, respiration rate 23 per minute, and body temperature $36.0^{\circ} \mathrm{C}$. Electrocardiogram showed sinus tachycardia and $\mathrm{Q}$ waves in the precordial leads $\left(\mathrm{V}_{2}\right.$ and $\left.\mathrm{V}_{3}\right)$. He was semicomatose and immediately intubated. extended focused assessment with sonography for trauma (E-FAST) performed by the trauma surgery department revealed massive hemopericardium and cardiac tamponade. The patient went into cardiac arrest and achieved return of spontaneous circulation after 1 cycle of cardiopulmonary resuscitation. He was moved to the operating 
room to undergo median sternotomy for release of hemopericardium by the trauma surgery department.

Anesthesia was induced with intravenous rocuronium and maintained with sevoflurane and a continuous infusion of sufentanil. A central venous catheter was placed through the right internal jugular vein, and a transesophageal echocardiographic probe was inserted. Along with hemopericardium, intraoperative TEE demonstrated a prolapsed tricuspid valve leaflet caused by chordal rupture that was not diagnosed in E-FAST (Fig. 1). Colorflow Doppler echocardiography showed severe tricuspid regurgitation (Fig. 2). Repair of tricuspid valve was performed after preparing and initiating cardiopulmonary bypass (CPB). Intraoperative findings were anterior and septal chordal rupture of the tricuspid valve and left atrium appendage rupture. Tricuspid

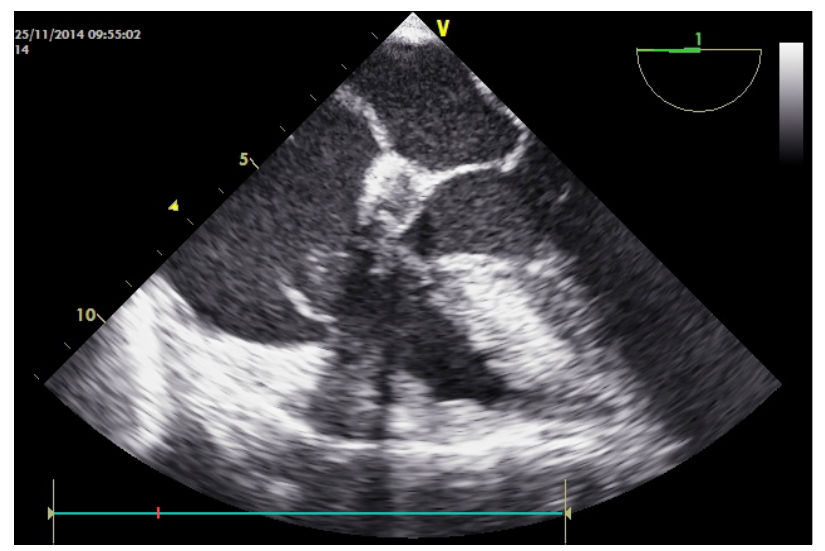

Fig. 1. The transesophageal echocardiography showed prolapse of the anterior and septal leaflet.

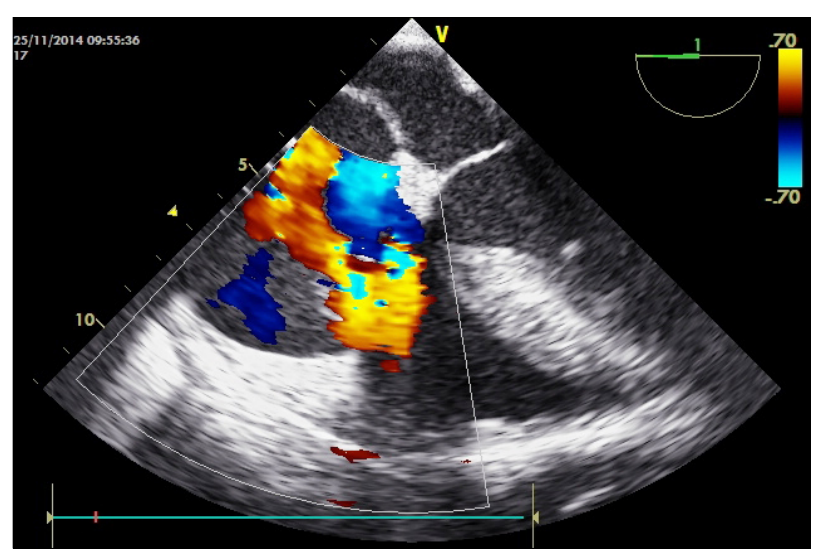

Fig. 2. The colorflow Doppler transesophageal echocardiography showed severe tricuspid regurgitation. valve repair and primary closure of the left atrial appendage was performed. Post-CPB TEE showed satisfactory leaflet coaptation and only mild tricuspid regurgitation remained (Fig. 3). Norepinephrine $(0.05 \sim 0.08 \mathrm{mcg} / \mathrm{kg} / \mathrm{min})$ was continuously infused for maintaining blood pressure during the post-bypass period. The patient was admitted to the trauma intensive care unit after surgery.

\section{Discussion}

Despite the rising incidence of traumatic tricuspid regurgitation secondary to blunt chest trauma during the last decade [3], slow pathology progression and the presence of more clinically acute lesions render its diagnosis difficult [4].

The right ventricle is vulnerable to injury because of anteroposterior compression from the adjacent sternum, especially during the end diastolic phase [5]. The decelerating force in the right ventricular chamber produces a regurgitation, thereby initiating rupture of the papillary muscle and/or chordae tendinae. The usual lesion observed at surgery is subvalvular rupture of the anterior papillary muscle [6]. Tricuspid leaflet prolapse, rupture of the chordae tendinae, and leaflet rupture have also been reported [7].

The timing of surgical intervention after traumatic tricuspid regurgitation is a subject of debate. However, the operation should be undertaken before right ventricular myocardial dysfunction, to facilitate valve repair rather than replacement [8]. Therefore, identification of a valve abnormality before development of symp-

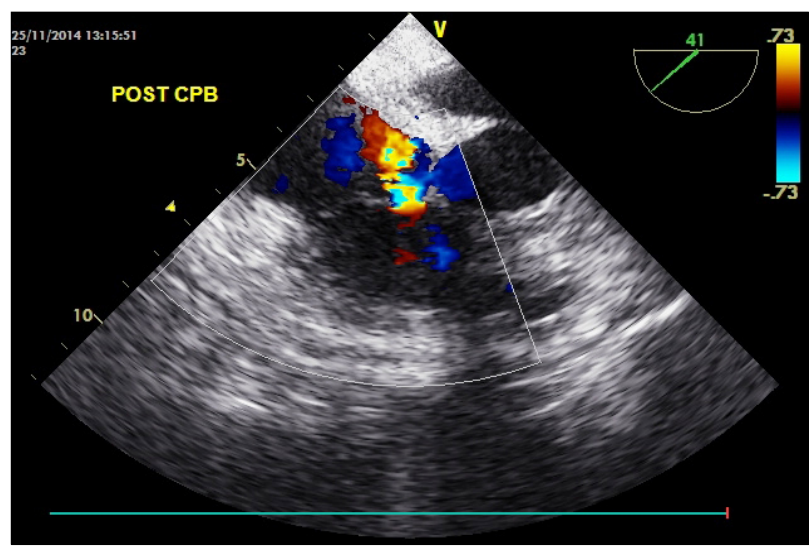

Fig. 3. The transesophageal echocardiography after tricuspid valve repair showed mild regurgitation. $\mathrm{CPB}$ : cardiopulmonary bypass. 
tomatic heart failure is optimal [9].

In the critically injured and hemodynamically unstable patient, FAST examination can be performed for a rapid assessment of peritoneal and/or pericardial fluid and provide critical information during the real time evaluation of complex trauma patients, directly at the bedside. Several studies demonstrate the feasibility and the rapid nature of performing the FAST examiantion [10]. However, there are some pitfalls of FAST; because of limitation to the pericardial sac, it is difficult to identify valvular or structural abnormalities by FAST [10]. In such cases, as exemplified here, intraoperative TEE can safely provide more information of cardiac anatomy involved in traumatic tricuspid regurgitation.

In the present case report, the patient suffered blunt chest trauma caused by a motor vehicle accident. Hemopericardium and cardiac tamponade were diagnosed by E-FAST but both tricuspid regurgitation and chordal rupture were missed in the emergency room. Tricuspid regurgitation and chordal rupture were identified by intraoperative TEE, and successful valve repair was undertaken before right ventricular deterioration. This case emphasizes that physicians should be aware of cardiac complications following blunt chest trauma and the use of TEE as a general diagnostic tool.

\section{Conflicts of Interest}

No potential conflict of interest relevant to this article was reported.

\section{References}

1. Schuster I, Graf S, Klaar U, Seitelberger R, Mundigler G, Binder T. Heterogeneity of traumatic injury of the tricuspid valve: a report of four cases. Wien Klin Wochenschr 2008; 120:499-503.

2. Gayet C, Pierre B, Delahaye JP, Champsaur G, Andre-Fouet $\mathrm{X}$, Rueff $\mathrm{P}$. Traumatic tricuspid insufficiency. An underdiagnosed disease. Chest 1987;92:429-32.

3. Lin SJ, Chen CW, Chou CJ, Liu KT, Su HM, Lin TH, et al. Traumatic tricuspid insufficiency with chordae tendinae rupture: a case report and literature review. Kaohsiung J Med Sci 2006;22:626-9.

4. Nelson M, Wells G. A case of traumatic tricuspid valve regurgitation caused by blunt chest trauma. J Am Soc Echocardiogr 2007;20:198.e4-5.

5. Krasna MJ, Flancbaum L. Blunt cardiac trauma: clinical manifestations and management. Semin Thorac Cardiovasc Surg 1992;4:195-202.

6. Richard P, Vayre F, Sabouret P, Gandjbakhch I, Ollivier JP. Outcome of traumatic tricuspid insufficiency, treated surgically. Apropos of 9 cases. Arch Mal Coeur Vaiss 1997;90:451-6.

7. Sugita T, Watarida S, Katsuyama K, Nakajima Y, Yamamoto R, Mori A. Valve repair with chordal replacement for traumatic tricuspid regurgitation. J Heart Valve Dis 1997;6:651-2.

8. van Son JA, Danielson GK, Schaff HV, Miller FA Jr. Traumatic tricuspid valve insufficiency. Experience in thirteen patients. J Thorac Cardiovasc Surg 1994;108:893-8.

9. Maisano F, Lorusso R, Sandrelli L, Torracca L, Coletti G, La Canna $G$, et al. Valve repair for traumatic tricuspid regurgitation. Eur J Cardiothorac Surg 1996;10:867-73.

10. Williams SR, Perera P, Gharahbaghian L. The FAST and EFAST in 2013: trauma ultrasonography: overview, practical techniques, controversies, and new frontiers. Crit Care Clin 2014;30:119-50. 